Journal of Advanced Research in Fluid Mechanics and Thermal Sciences

\title{
Skin Temperature Distribution on Simulation Thermal Effects Under Construction Climate
}

\author{
Ahmad Rasdan Ismail ${ }^{1,2^{*}}$, Norfadzilah Jusoh², Nor Kamilah Makhtar ${ }^{3}$, Raemy Md Zein ${ }^{4}$, Nurul Husna \\ Che Hassan ${ }^{1}$, Nor Kamaliana Khamis ${ }^{5}$ \\ 1 Faculty of Creative Technology \& Heritage, Universiti Malaysia Kelantan, 16300 Bachok, Kelantan, Malaysia \\ 2 Centre for Management of Environment, Occupational Safety and Health (CMeOSH), Universiti Malaysia Kelantan, 16300 Bachok, Kelantan, \\ Malaysia \\ 3 Department of Educational Planning and Research, Institute of Teacher Education, Campus Kota Bharu, Kota Bharu, Kelantan, Malaysia \\ 4 National Institute of Occupational Safety and Health (NIOSH), 43650 Bandar Baru Bangi, Selangor, Malaysia \\ 5 Department of Mechanical and Manufacturing Engineering, Faculty of Engineering and Built Environment, Unversiti Kebangsaan Malaysia, \\ Bandar Baru Bangi, Selangor, Malaysia
}

\section{ARTICLE INFO ABSTRACT}

\section{Article history:}

Received 11 April 2021

Received in revised form 10 July 2021

Accepted 15 July 2021

Available online 19 August 2021

\section{Keywords:}

Skin temperature; construction workers; simulation; thermal; climate

\begin{abstract}
Global warming is bringing more frequent and severe heat waves. Construction workers are particularly vulnerable to heat risk due to the job culture in the outdoor environment. Unrestrained heat has extreme effects on skin temperature, which will lead to low performance and also results to injuries and fatalities. This study aims to investigate the distribution of skin surface temperature under seven different thermal conditions involving variations in temperature and relative humidity. The computational simulation models based on real construction climate were developed. Simulation results showed the highest heat index (a combination of temperature/relative humidity) is at $34^{\circ} \mathrm{C} / 92 \%$ and $38{ }^{\circ} \mathrm{C} / 83 \%$ and fall under extreme danger category. At this level, the models were experienced high heat/sunstroke continuous exposure. This study also indicated that skin temperature has significantly influenced by the hot and humid environment. It is hoped that this study is able to provide guidance and reference to the industry, especially the construction sector by providing appropriate control measures to overcome the issue of heat risk among workers.
\end{abstract}

\section{Introduction}

Tropical countries recognize as the region which have abundant of solar radiation and the relatively high air temperature and relative humidity levels. Hence, long periods of outdoor thermal discomfort are common [1,2]. Malaysia also located in a tropical region. Malaysia has a tropical rainforest climate with relatively high air temperature, relative humidity, and solar radiation. With $27^{\circ} \mathrm{C}$ as yearly mean air temperature, the monthly mean maximum temperatures vary from $33.5^{\circ} \mathrm{C}$ in March/April to $31.9^{\circ} \mathrm{C}$ in December. On the other hand, the monthly mean minimum temperatures

\footnotetext{
* Corresponding author.

E-mail address: rasdan@umk.edu.my

https://doi.org/10.37934/arfmts.86.1.154163
} 
range from $23.1{ }^{\circ} \mathrm{C}$ in January to $24.3^{\circ} \mathrm{C}$ in May. The relative humidity generally reaches a maximum above $90 \%$, although its mean is between $70 \%$ and $90 \%$. Likewise, with high rates of solar radiation (mean: from 14 to $16 \mathrm{MJ} / \mathrm{m} 2 \mathrm{~d}$ ), the wind velocity is usually insignificant although during the monsoon seasons, it slightly increases [3,4]. To conclude, commonly high air temperature and relative humidity, intensified solar radiation, and generally over cast sky coverage as well as insignificant wind velocity besides heavy rainfalls distinguish the microclimate of this tropical region.

With the rapid development of construction in Malaysia, measures taken to adjust the environment have played an increasingly vital role in ensuring the health and safety of workers. Industrial workers are easier to expose to discomfort and pain during work [5]. Sun and Zhu [6] reviewed many studies on human physiological and psychological response to hot and humid environments. Their results indicated that high temperature and humidity can significantly reduce the temperature difference in vitro and in vivo, as well as affect metabolic heat diffusion, cause heart failure, increase oxygen consumption, and lead to the onset of other physiological responses. Kielblock et al., [7] identified that the increase in ambient temperature and relative humidity inside a refuge chamber appreciably affects human metabolism. O'Nealet and Bishop [8] conducted experiments using multifarious, but simple, mental performance tests under hot and humid environments. The results showed that consciousness was one of the major factors that were obviously influenced by manual labor in hot and humid environments.

As part of the thermoregulatory process, the human body skin is constantly transferring heat with the surrounding environment. In a thermally comfortable state, substantial differences in the skin temperatures exist across the body, with higher temperatures at the head and torso and lower at the feet and hands. A human body heat loss is governed by a combination of several heat transfer mechanisms such as convection, radiation, respiration and evaporation. As technology has advanced, thermal manikins are the most realistic devices widely used for the assessment of heat and mass transfer from the human body to the environment. Their anatomic shape and their ability to sweat and move provide experimental conditions that are closer to the real human [9]. The number of thermal manikins available and the diversity of their use in research and measurement standards have increased continuously over the past 60 years $[10,11]$. In this time, the manikin technology has advanced either by improving precision [12] or by reducing production costs [13]. Thermal manikins have proved to be helpful to assess the indoor air quality $[14,15]$, the spread of airborne particles [16-18], and also to calculate the human environment heat transfer coefficients used in numerical simulations of indoor spaces with occupants $[19,20]$.

An evaluation of thermal conditions in industry can be done in one of the following; by using human subjects or by direct measurement of microclimate physical activities or by human shaped or called thermal manikins. Apart from experimental methods, there are usually used computational fluid dynamic (CFD) techniques. As a cost-efficient approach, CFD has been widely employed in the research area of heat transfer in thermal conditions. The human interacts closely with their surroundings by serving as obstacles of airflow, and the major heat source of thermal buoyancy flows [21]. In this work, the purpose of this paper is to investigate the distribution of skin surface temperature under different temperature and different relative humidity.

\section{Methodology}

\subsection{Experimental Facility}

Climate chamber, as shown in Figure 1 with sizing of $4.07 \mathrm{~m}(\mathrm{~L}) \times 4.07 \mathrm{~m}(\mathrm{~W}) \times 2.5(\mathrm{H})$ was used as the simulated working environments. In this study, we adopted seven temperature levels with a combination relative humidity. The designed conditions of simulation for the study construct based 
on the design of experiment method and based real case of construction industry climate indicated in Table 1.

Table $\mathbf{1}$
Studied thermal conditions set up
\begin{tabular}{lll}
\hline No. & Temperature, ${ }^{\circ} \mathrm{C}$ & Relative Humidity, $\%$ \\
\hline 1 & 25 & 70 \\
2 & 27 & 50 \\
3 & 27 & 78 \\
4 & 32 & 70 \\
5 & 34 & 74 \\
6 & 34 & 92 \\
7 & 38 & 83 \\
\hline
\end{tabular}

This study simulates the manual lifting task at construction industry. In the construction industry, the subjects are demanded to lift a sandbag manually. Therefore, in this study, the weight of the sandbag used is $10 \mathrm{~kg}$ to follow the guideline with much lower weight than the maximum [22].

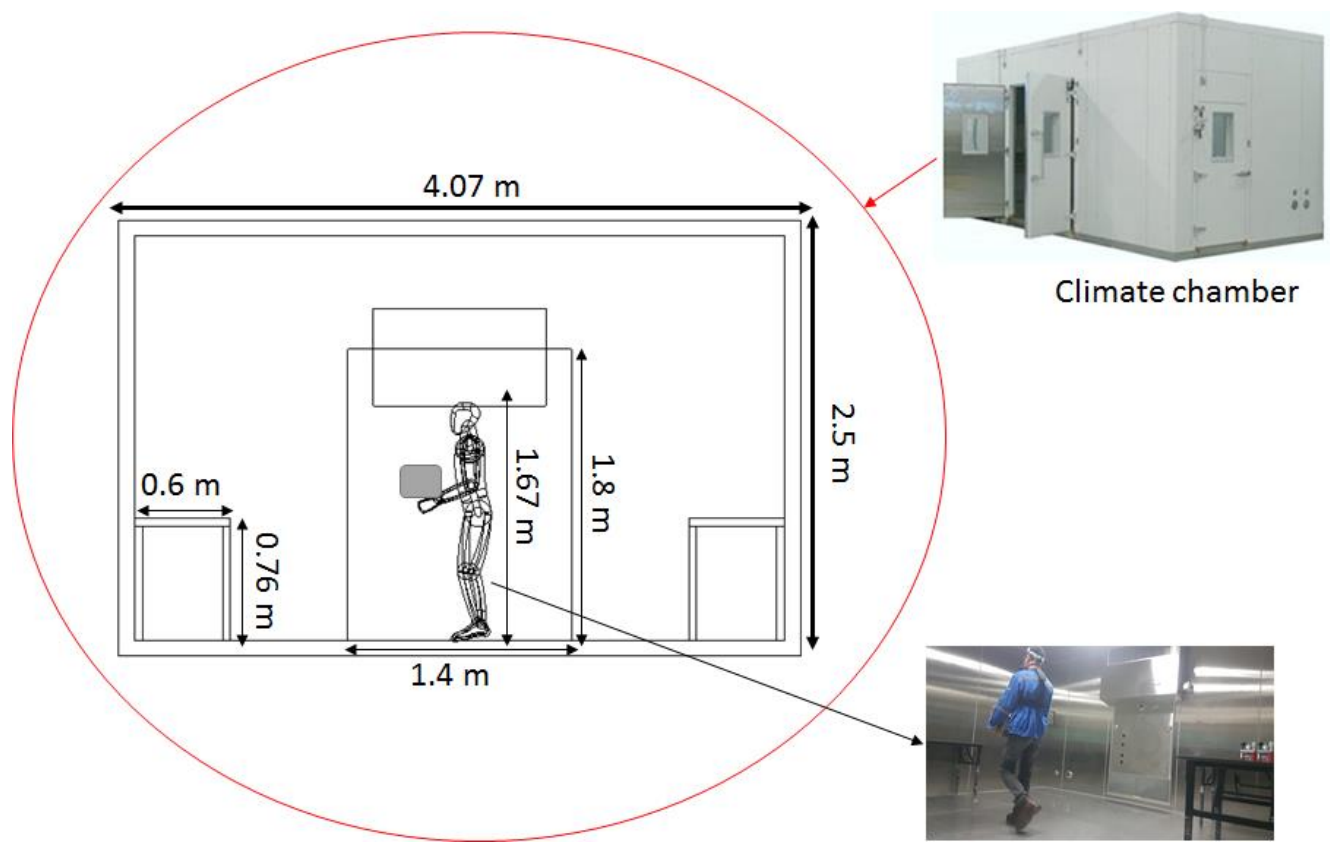

Fig. 1. Computational domain

\subsection{Boundary Conditions of CFD Model}

Figure 2 present the boundary setting of the working environment. In this study, the ANSYS CFD software program was used to explore a three-dimensional model with steady-state, threedimensional and non-isothermal conditions assumptions. Thus, the RNG $k-\varepsilon$ turbulence model was applied to model air turbulence as described in a study by Chen [23], which examined indoor air flow under different turbulence models and concluded that the RNG k- $\varepsilon$ model was the most accurate model in terms of flow separation, streamline curvature, and flow stagnation.

The boundary conditions in the initial set of the simulations were chosen according to the conditions in the experiment by Nilsson et al., [24,25]. The walls were modelled as no-slip walls with constant, and the evaluated value of wall emissivity was 0.9 . The boundary conditions (Figure 2 ) at 
the inlet were the velocity of $0.1 \mathrm{~m} / \mathrm{s}$ with mean turbulence intensity of $6 \%$ (experimental data, [26]). The air was evacuated through two circular openings on the wall.

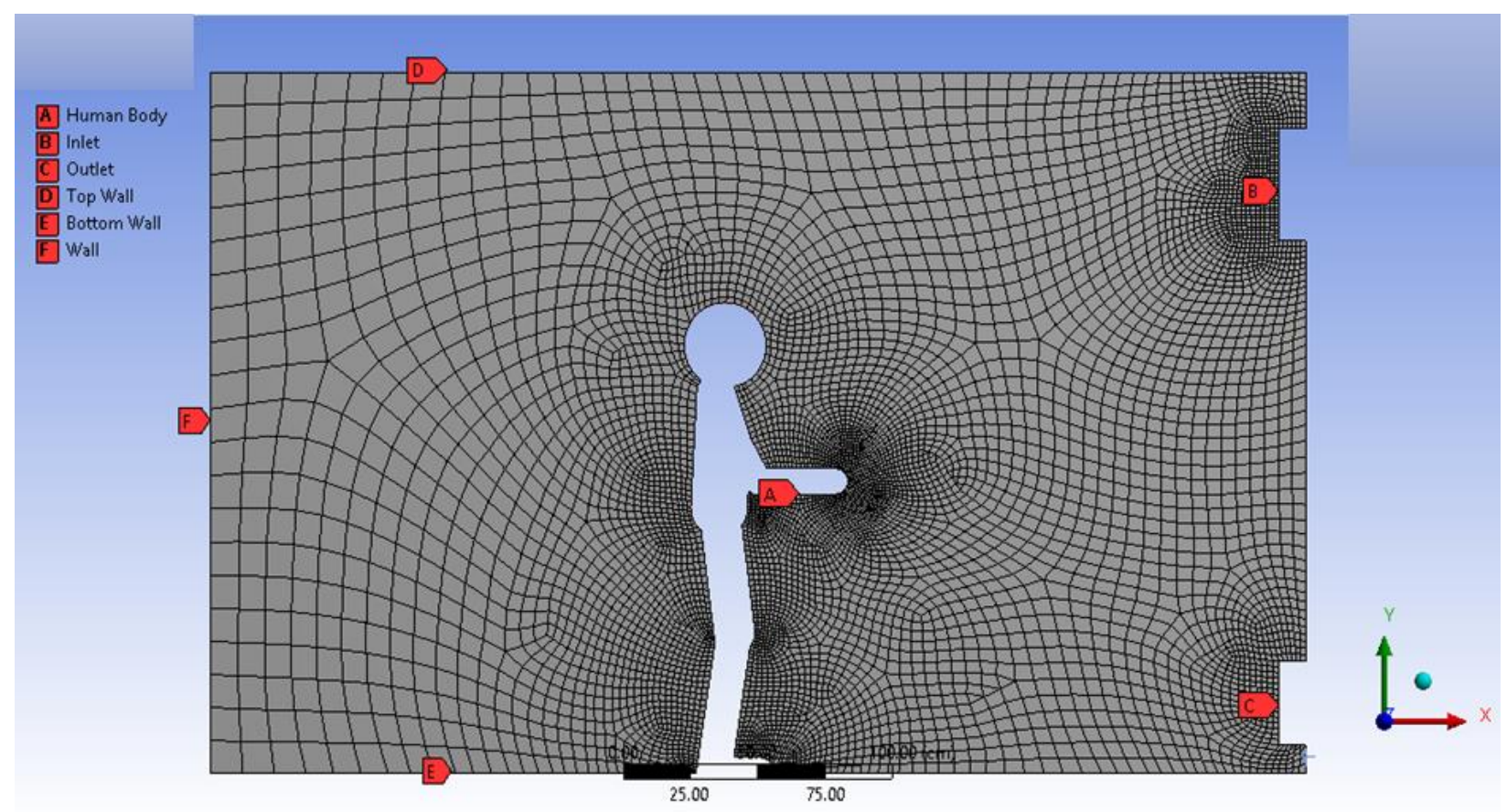

Fig. 2. Mesh with boundary conditions

\subsection{Numerical Methodology}

The flow of air in the climate chamber was consider as steady, incompressible, low-velocity turbulent flow. The governing equations include the mass conservation, momentum conservation, energy conservation and species diffusion equations are as follows [27]

$\frac{\partial \rho}{\partial \tau}+\frac{\partial \rho u_{i}}{\partial x_{i}}=0$

$\frac{\partial \rho u_{i}}{\partial \tau}+\frac{\partial \rho u_{j} u_{i}}{\partial x_{j}}=\frac{\partial \tau j_{i}}{\partial x_{j}}+\rho f_{i}$

$\frac{\partial \rho t}{\partial \tau}+\frac{\partial \rho u_{i} t}{\partial x_{i}}=\frac{\partial}{\partial x_{i}}(k+k i) \frac{\partial t}{\partial x_{i}}+S_{h}$

$\frac{\partial \rho m_{l}}{\partial \tau}+\frac{\partial \rho u_{i} m_{l}}{\partial x}=\frac{\partial}{\partial x}\left(D_{l} \frac{\partial m_{l}}{\partial x_{i}}\right)+S_{l}$

where $\rho$ is air density, $u i$ is the velocity. $f i$ is unit mass force, $\tau j i$ is air Viscous stress. $k$ is heat conductivity coefficient, $k i$ is thermal conductivity due to the effect of turbulence, $\mathrm{ml}$ is the mass of component, I per unit volume, $D /$ is diffusion coefficient, $S /$ is the rate of formation of components per unit volume. The convergence of the solution and relevant variables were monitored and the solution was completed when there were no changes between iterations (Figure. 3). In addition, the effects of conservation were also checked. Constitutive equations were proposed to describe the flow and heat transfer mechanism such as power-law fluid model in various of shear stress according to power function of strain rate [28]. 


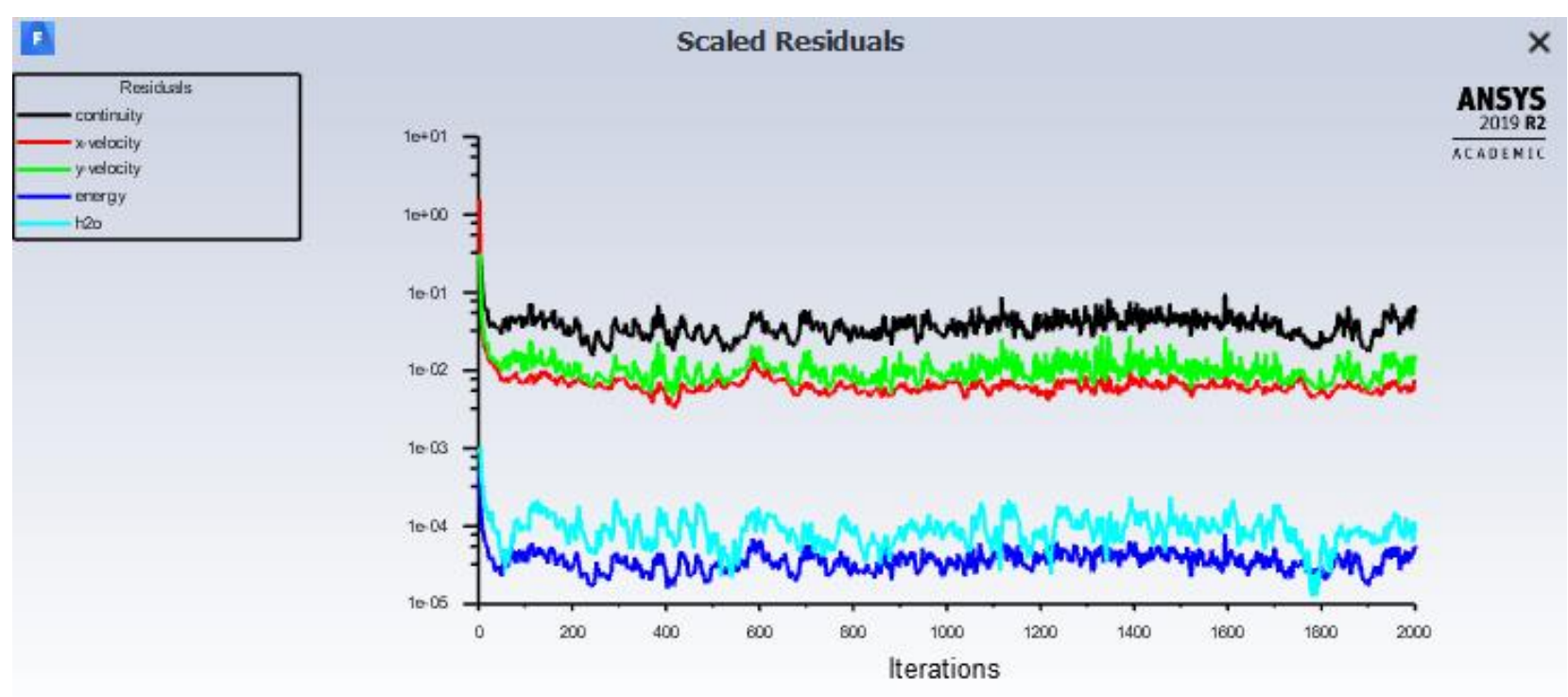

Fig. 3. Solution convergence

\section{Results}

In Figure 4, the left side of the plot shows the scale of airflow temperature in ${ }^{\circ} \mathrm{C}$. The effects of supply temperature and relative humidity, flow pattern measuring parameters are investigated. The contour plot in the fluid domain is colour coded and related to the CFD colour map, ranging from 25.0 to $37.0^{\circ} \mathrm{C}$. Figure $4(\mathrm{a})$ present the air temperature supply is $25^{\circ} \mathrm{C}$, and this figure shows that the temperature increases to the behind of the manikin from the supply level. As observed, the temperature around the manikin range between 32.2 to $37.0^{\circ} \mathrm{C}$. For this case study, the lower temperature was observed near the inlet, which is $26.2^{\circ} \mathrm{C}$. The gradient of the temperature increase with the distance from the inlet where the heat source (manikin) exist is strongly higher than the gradient in the space of the environmental chamber. It was also observed that the temperature near the wall behind the manikin was higher than the area near the inlets, which is $33.4{ }^{\circ} \mathrm{C}$ and $28.6{ }^{\circ} \mathrm{C}$.

Figure $4(\mathrm{~b})$ present the air temperature supply is $27{ }^{\circ} \mathrm{C}$, and this result shows that the temperature increases slowly to the behind of the manikin from the supply level. As observed, the temperature around the manikin range between 35.0 to $37.0{ }^{\circ} \mathrm{C}$. For this study, the lower temperature was observed near the inlet, which is $26.8^{\circ} \mathrm{C}$. The gradient of the temperature increase with the distance from the inlet where the heat source (manikin) exist is strongly higher than the gradient in the space of the environmental chamber. It was also observed that the temperature near the wall behind the manikin was higher than the area near the inlets, which is $34.0^{\circ} \mathrm{C}$ and $28.9^{\circ} \mathrm{C}$.

Figure 4 (c) present the air temperature supply is $27^{\circ} \mathrm{C}$, and this result shows that the temperature slightly increases to the behind of the manikin from the supply level. As observed, the temperature around the manikin range between 34.0 to $37.0^{\circ} \mathrm{C}$. For this case study, the lower temperature was observed near the inlet, which is $27.9^{\circ} \mathrm{C}$. The gradient of the temperature increase with the distance from the inlet where the heat source (manikin) exist is strongly higher than the gradient in the space of the environmental chamber. It was also observed that the temperature near the wall behind the manikin was higher than the area near the inlets, which is $34.0^{\circ} \mathrm{C}$ and $28.9^{\circ} \mathrm{C}$.

Figure $4(\mathrm{~d})$ present the air temperature supply is $32^{\circ} \mathrm{C}$. The contour plot in the fluid domain is colour coded and related to the CFD colour map, ranging from 31.9 to $37.0^{\circ} \mathrm{C}$, and the result shows that the temperature increases slowly to the behind of the manikin from the supply level. As observed, the temperature around the manikin range between 36.0 to $37.0^{\circ} \mathrm{C}$. For this case study, 
the lower temperature was observed near the inlet, which is $31.9^{\circ} \mathrm{C}$. The gradient of the temperature increase with the distance from the inlet where the heat source (manikin) exist is strongly higher than the gradient in the space of the environmental chamber. It was also observed that the temperature near the wall behind the manikin was higher than the area near the inlets, which is $35.0^{\circ} \mathrm{C}$ and 32.9 ${ }^{\circ} \mathrm{C}$.

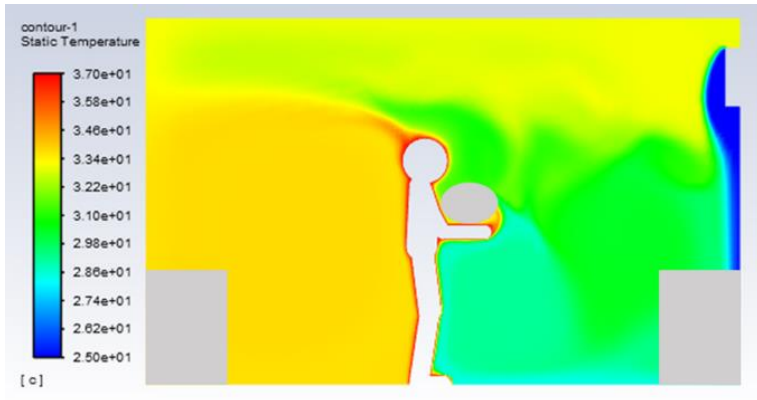

(a) $25 / 70 \%$

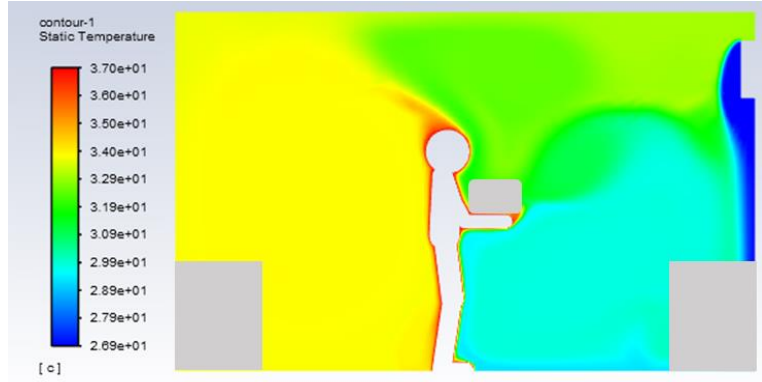

(c) $27 / 78 \%$

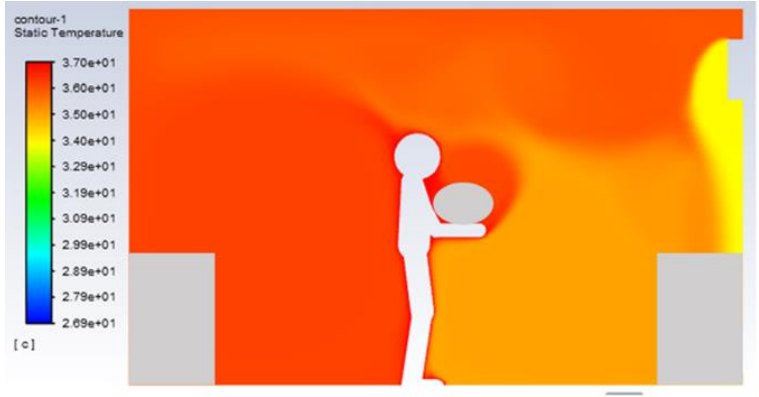

(e) $34 / 74 \%$

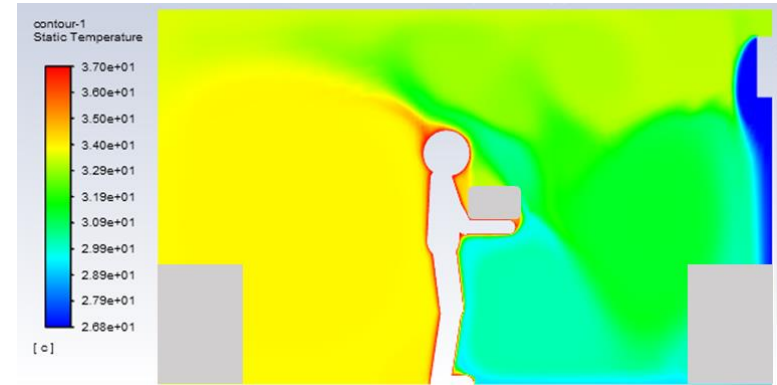

(b) $27 / 50 \%$

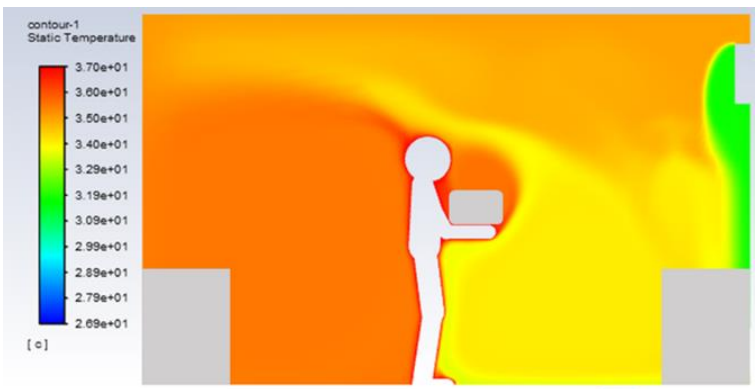

(d) $32 / 70 \%$

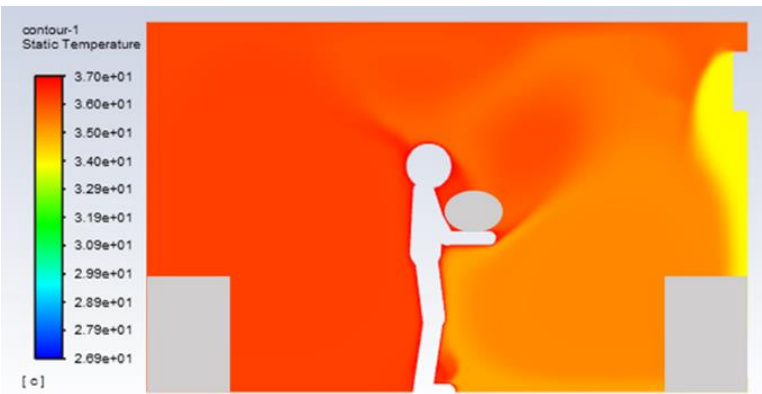

(f) $34 / 92 \%$

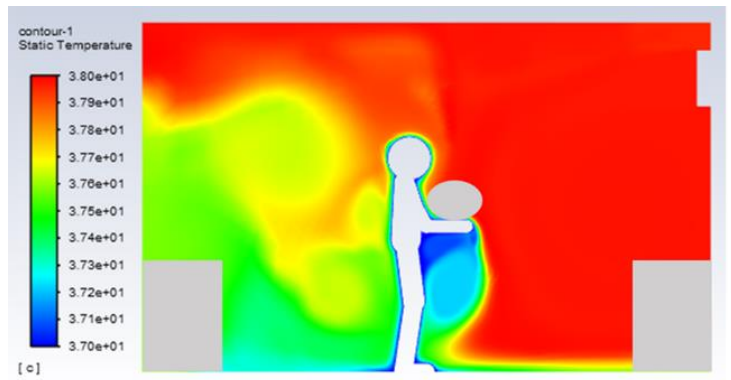

(g) $38 / 83 \%$

Fig. 4. The distribution of the temperature during work task

Figure 4(e) present the air temperature supply is $34{ }^{\circ} \mathrm{C}$. The contour plot in the fluid domain is colour coded and related to the CFD colour map, ranging from 34.0 to $37.0^{\circ} \mathrm{C}$, and the result shows that the temperature increases to the behind of the manikin from the supply level. As observed, the temperature around the manikin range between 35.0 to $37.0^{\circ} \mathrm{C}$. For this case study, the lower 
temperature was observed near the inlet, which is $34.0^{\circ} \mathrm{C}$. The gradient of the temperature increase with the distance from the inlet where the heat source (manikin) exist is strongly higher than the gradient in the space of the environmental chamber. It was also observed that the temperature near the wall behind the manikin was higher than the area near the inlets, which is $37.0^{\circ} \mathrm{C}$ and $34.0^{\circ} \mathrm{C}$.

Figure $4(\mathrm{f})$ present the air temperature supply is $34^{\circ} \mathrm{C}$. The contour plot in the fluid domain is colour coded and related to the CFD colour map, ranging from 34.0 to $37.0^{\circ} \mathrm{C}$ and the result shows that the temperature increases to the behind of the manikin from the supply level. As observed, the temperature around the manikin range between 36.0 to $37.0^{\circ} \mathrm{C}$. For this case study, the lower temperature was observed near the inlet, which is $34.0^{\circ} \mathrm{C}$. The gradient of the temperature increase with the distance from the inlet where the heat source (manikin) exist is strongly higher than the gradient in the space of the environmental chamber. It was also observed that the temperature near the wall behind the manikin was higher than the area near the inlets, which is $37.0^{\circ} \mathrm{C}$ and $34.5^{\circ} \mathrm{C}$.

Figure $4(\mathrm{~g})$ present the air temperature supply is $38^{\circ} \mathrm{C}$. The contour plot in the fluid domain is colour coded and related to the CFD colour map, ranging from 37.0 to $38.0^{\circ} \mathrm{C}$., and the result shows that the temperature decreases to the behind of the manikin from the supply level. As observed, the temperature around the manikin range between 37.3 to $37.7{ }^{\circ} \mathrm{C}$. For this case study, the lower temperature was observed near the wall behind of the manikin, which is $37.4^{\circ} \mathrm{C}$. The gradient of the temperature increase with the distance from the inlet where the heat source (manikin) exist is strongly higher than the gradient in the space of the environmental chamber. It was also observed that the temperature near the wall behind the manikin was lower than the area near the inlets, which is $37.4^{\circ} \mathrm{C}$ and $38.0^{\circ} \mathrm{C}$. The skin temperature in this thermal condition was higher than other thermal conditions. It is thought that the skin temperature is influenced by the high temperature.

\section{Discussion}

Comparing with other parts, the skin temperatures of the hand and foot changed greater, while the skin temperatures of the chest, back, waist and abdomen changed less. A similar observation was made by Liu et al., [29] that because of a relationship with the distribution of vessels and blood flow. When the ambient temperature is higher than skin temperature, the human body absorbs heat from its ambient environment and evaporation is the sole avenue of heat dissipation from the skin. This study agrees with Luo et al., [30] stated that it is supposed that for the higher climate set points, the temperature differences between the skin. The manikin temperature for hand and feet are lower than in other parts. The reason may be due to the different flow fields. The flow field around the human body is highly dependent on the detailed profile of the body, for instance, the manikin temperature around the arms and feet can be lower than manikin temperature around the back part due to the block of the inlet to the flowing air. The surface temperature within one segment was found quite a bit. According to Kong et al., [31], the non-uniform surface temperature distribution was confirmed, and at least a $1.0^{\circ} \mathrm{C}$ surface temperature difference was found on almost all the segments. Each segment always had a higher temperature in the central part and the lower temperature at the edge. This study showed a significant with the previous study stated that the body feature difference of thermal manikins could directly affect the airflow field in the vicinity of the Computational Thermal Manikins (CTMs) and its impact would be enlarged in the upper regions due to the development of the buoyancy-driven thermal plume [32].

Table 2 presents the skin temperature phenomena occurred during the seven thermal conditions setting. As seen, increasing the temperature from 25 to $38^{\circ} \mathrm{C}$, linearly increased the average skin temperature from 31.7 to $37.8^{\circ} \mathrm{C}$. Both temperature and relative humidity had a significant impact on skin temperature. The skin temperature slightly increases with increasing relative humidity; when 
temperature was $27^{\circ} \mathrm{C}$, the skin temperature changed significantly when relative humidity increased from $50 \%$ to $78 \%$. Also, when temperature was $34{ }^{\circ} \mathrm{C}$, the skin temperature changed significantly when relative humidity $(\mathrm{RH})$ increased from $74 \%$ to $92 \%$. These results were similar with Jin et al., [33] that indicated that the greater the increase of the skin temperature caused by an increase in $\mathrm{RH}$. Atmaca and Yigit [34] investigated skin temperature and operative temperature was 26, 30 and 34 ${ }^{\circ} \mathrm{C}$. Therefore, the author compared the skin temperature in this study with the experimental data obtained by Atmaca and Yigit. When the temperature was $34^{\circ} \mathrm{C}$, in this study skin temperature was $35.6{ }^{\circ} \mathrm{C}$, meanwhile study by Atmaca and Yigit was $35.1^{\circ} \mathrm{C}$. According to NWS [35], the higher heat index (a combination of temperature/relative humidity) is $34{ }^{\circ} \mathrm{C} / 92 \%$ and $38{ }^{\circ} \mathrm{C} / 83 \%$ in category extreme danger. In this level, the workers feel heat/sunstroke highly likely with continued exposure. Based on simulation data under high temperature and high relative humidity as a tropical climate is a concern. The heat transfer reveals that the skin experiencing high temperature and high relative humidity at the skin temperature of $35.7^{\circ} \mathrm{C}$ and $37.8^{\circ} \mathrm{C}$. Meanwhile, the second higher heat index (a combination of temperature and humidity) is $34^{\circ} \mathrm{C} / 74 \%$ in category danger at the skin temperature of $35.6^{\circ} \mathrm{C}$.

Table 2

The summary of results skin temperature

\begin{tabular}{llll}
\hline No. & Temperature, ${ }^{\circ} \mathrm{C}$ & Relative Humidity, $\%$ & Skin temperature, ${ }^{\circ} \mathrm{C}$ \\
\hline 1 & 25 & 70 & 31.7 \\
2 & 27 & 50 & 31.9 \\
3 & 27 & 78 & 32.2 \\
4 & 32 & 70 & 34.7 \\
5 & 34 & 74 & 35.6 \\
6 & 34 & 92 & 35.7 \\
7 & 38 & 83 & 37.8 \\
\hline
\end{tabular}

\section{Conclusions}

In this study, skin temperature in a simulated heat-exposure experiment in a well-controlled climate chamber were compared with different conditions. The CFD results reveal that all seven conditions provide an effect to the workers in the construction. The heat index shows that when the human working in a hot climate, they feel heat/sunstroke highly or feel heat cramps, or heat exhaustion and heatstroke. This study has shown that skin temperature was influenced significantly by the hot and humid environment.

\section{Acknowledgement}

The authors would like to acknowledge the assistance or encouragement from National Institute of Occupational Safety and Health (NIOSH) Malaysia in providing the technical and financial support to Universiti Malaysia Kelantan (UMK) in conducting this research.

\section{References}

[1] Ahmed, Khandaker Shabbir. "Comfort in urban spaces: defining the boundaries of outdoor thermal comfort for the tropical urban environments." Energy and Buildings 35, no. 1 (2003): 103-110. https://doi.org/10.1016/S03787788(02)00085-3

[2] Niu, Jianlei, Jianlin Liu, Tsz-cheung Lee, Zhang John Lin, Cheukming Mak, Kam-Tim Tse, Bo-sin Tang, and Kenny CS Kwok. "A new method to assess spatial variations of outdoor thermal comfort: Onsite monitoring results and implications for precinct planning." Building and Environment 91 (2015): $263-270$. https://doi.org/10.1016/j.buildenv.2015.02.017 
[3] Makaremi, Nastaran, Elias Salleh, Mohammad Zaky Jaafar, and AmirHosein GhaffarianHoseini. "Thermal comfort conditions of shaded outdoor spaces in hot and humid climate of Malaysia." Building and environment 48 (2012): 7-14. https://doi.org/10.1016/j.buildenv.2011.07.024

[4] Ghaffarianhoseini, Amirhosein, Umberto Berardi, and Ali Ghaffarianhoseini. "Thermal performance characteristics of unshaded courtyards in hot and humid climates." Building and Environment 87 (2015): 154-168. https://doi.org/10.1016/i.buildenv.2015.02.001

[5] Ismail, Ahmad Rasdan, Khairul Azhar Mat Daud, Nik Zulkarnaen Khidzir, and Mohd Firuz Mohd Anwar. "Application of visual computer simulation in industrial ergonomics." International Journal of Creative Future and Heritage (TENIAT) 2, no. 1 (2014): 1-13.

[6] Sun, Yu Ping, and Neng Zhu. "Study on assessment of high temperature and humidity in working environment on human health." In Advanced Materials Research, vol. 610, pp. 739-742. Trans Tech Publications Ltd, 2013. https://doi.org/10.4028/www.scientific.net/AMR.610-613.739

[7] Kielblock, A. J., J. P. Van Rensburg, A. Van Der Linde, A. J. Van Rensburg, H. Russell, H. Rust, and C. Haven. "The functional performance of formal gold mine and colliery refuge bays with special reference to air supply failure." $J$. Mine Vent. Soc. S. Afr.;(South Africa) 41, no. 5 (1988).

[8] O'Neal, E. K., and P. Bishop. "Effects of work in a hot environment on repeated performances of multiple types of simple mental tasks." International Journal of Industrial Ergonomics 40, no. 1 (2010): 77-81. https://doi.org/10.1016/j.ergon.2009.07.002

[9] Psikuta, Agnes, Jonas Allegrini, Barbara Koelblen, Anna Bogdan, Simon Annaheim, Natividad Martínez, Dominique Derome, Jan Carmeliet, and René M. Rossi. "Thermal manikins controlled by human thermoregulation models for energy efficiency and thermal comfort research-a review." Renewable and Sustainable Energy Reviews 78 (2017): 1315-1330. https://doi.org/10.1016/i.rser.2017.04.115

[10] Holmér, Ingvar. "Thermal manikin history and applications." European journal of applied physiology 92, no. 6 (2004): 614-618. https://doi.org/10.1007/s00421-004-1135-0

[11] Wyon, David P. "Use of thermal manikins in environmental ergonomics." Scandinavian journal of work, environment \& health (1989): 84-94.

[12] Psikuta, Agnes, Kalev Kuklane, Anna Bogdan, George Havenith, Simon Annaheim, and René M. Rossi. "Opportunities and constraints of presently used thermal manikins for thermo-physiological simulation of the human body." International journal of biometeorology 60, no. 3 (2016): 435-446. https://doi.org/10.1007/s00484$\underline{015-1041-7}$

[13] Fan, Jintu, and Y. S. Chen. "Measurement of clothing thermal insulation and moisture vapour resistance using a novel perspiring fabric thermal manikin." Measurement Science and Technology 13, no. 7 (2002): 1115. https://doi.org/10.1088/0957-0233/13/7/320

[14] Xing, Huijuan, Andy Hatton, and Hazim B. Awbi. "A study of the air quality in the breathing zone in a room with displacement ventilation." Building and environment 36, no. 7 (2001): 809-820. https://doi.org/10.1016/S03601323(01)00006-3

[15] Melikov, A., and J. Kaczmarczyk. "Measurement and prediction of indoor air quality using a breathing thermal manikin." Indoor air 17, no. 1 (2007): 50-59. https://doi.org/10.1111/j.1600-0668.2006.00451.x

[16] Brohus, Henrik, and Peter V. Nielsen. "Personal exposure in displacement ventilated rooms." Indoor Air 6, no. 3 (1996): 157-167. https://doi.org/10.1111/j.1600-0668.1996.t01-1-00003.x

[17] Brohus, Henrik. "Measurement of indoor air quality by means of a breathing thermal manikin." (2000).

[18] Shi, Shanshan, Yin Li, and Bin Zhao. "Deposition velocity of fine and ultrafine particles onto manikin surfaces in indoor environment of different facial air speeds." Building and environment 81 (2014): $388-395$. https://doi.org/10.1016/i.buildenv.2014.07.017

[19] De Dear, Richard J., Edward Arens, Zhang Hui, and Masayuki Oguro. "Convective and radiative heat transfer coefficients for individual human body segments." International Journal of Biometeorology 40, no. 3 (1997): 141156. https://doi.org/10.1007/s004840050035

[20] Quintela, Divo, Adélio Gaspar, and Carlos Borges. "Analysis of sensible heat exchanges from a thermal manikin." European journal of applied physiology 92, no. 6 (2004): 663-668. https://doi.org/10.1007/s00421-004$\underline{1132-3}$

[21] Zukowska, Daria, Zbigniew Popiolek, and Arsen Melikov. "Impact of personal factors and furniture arrangement on the thermal plume above a human body." In Proc Roomvent, vol. 7, pp. 137-144. 2007.

[22] Department of Occupational Safety and Health (DOSH) 2018 Guidelines for Manual Handling at Workplace.

[23] Chen, Qingyan. "Comparison of different k- $\varepsilon$ models for indoor air flow computations." Numerical Heat Transfer, Part B Fundamentals 28, no. 3 (1995): 353-369. https://doi.org/10.1080/10407799508928838

[24] Nilsson, Håkan O., Henrik Brohus, and Peter V. Nielsen. "CFD modeling of thermal manikin heat loss in a comfort evaluation benchmark test." In Proceedings of Roomvent 2007: Helsinki 13-15 June 2007. FINVAC ry, 2007. 
[25] Nilsson, Håkan O., Henrik Brohus, and Peter V. Nielsen. "Benchmark: Benchmark Test for a Computer Simulated Person: Manikin Heat Loss for Thermal Comfort Evaluation: Versioon of February 2007." (2007).

[26] Luo, N., W. G. Weng, M. Fu, J. Yang, and Z. Y. Han. "Experimental study of the effects of human movement on the convective heat transfer coefficient." Experimental thermal and fluid science 57 (2014): 40-56. https://doi.org/10.1016/j.expthermflusci.2014.04.001

[27] Versteeg, Henk Kaarle, and Weeratunge Malalasekera. An introduction to computational fluid dynamics: the finite volume method. Pearson education, 2007.

[28] Ferdows, Mohammad, Mohammed Shamshuddin, and Khairy Zaimi. "Computation of Steady Free Convective Boundary Layer Viscous Fluid Flow and Heat Transfer towards the Moving Flat subjected to Suction/Injection Effects." CFD Letters 13, no. 3 (2021): 16-24. https://doi.org/10.37934/cfdl.13.3.1624

[29] Liu, Yanfeng, Lijuan Wang, Jiaping Liu, and Yuhui Di. "A study of human skin and surface temperatures in stable and unstable thermal environments." Journal of thermal Biology 38, no. 7 (2013): $440-448$. https://doi.org/10.1016/i.jtherbio.2013.06.006

[30] Luo, N., W. G. Weng, M. Fu, J. Yang, and Z. Y. Han. "Experimental study of the effects of human movement on the convective heat transfer coefficient." Experimental thermal and fluid science 57 (2014): 40-56. https://doi.org/10.1016/i.expthermflusci.2014.04.001

[31] Kong, Meng, Thong Q. Dang, Jianshun Zhang, and H. Ezzat Khalifa. "Micro-environmental control for efficient local cooling." Building and Environment 118 (2017): 300-312. https://doi.org/10.1016/j.buildenv.2017.03.040

[32] Yan, Yihuan, Xiangdong Li, Lin Yang, and Jiyuan Tu. "Evaluation of manikin simplification methods for CFD simulations in occupied indoor environments." Energy and Buildings 127 (2016): 611-626. https://doi.org/10.1016/i.enbuild.2016.06.030

[33] Jin, Ling, Yufeng Zhang, and Zhongjun Zhang. "Human responses to high humidity in elevated temperatures for people in hot-humid climates." Building and Environment 114 (2017): 257-266. https://doi.org/10.1016/i.buildenv.2016.12.028

[34] Atmaca, Ibrahim, and Abdulvahap Yigit. "Predicting the effect of relative humidity on skin temperature and skin wettedness." Journal of Thermal Biology 31, no. 5 (2006): 442-452. https://doi.org/10.1016/i.jtherbio.2006.03.003

[35] National Weather Services (NWS). "Beat the heat weather ready nation campaign. National Oceanic and Atmospheric Administration." 2014. 